Supporting Information

\title{
Synergistic Deep Eutectic Solvents for Lithium Extraction
}

Takafumi Hanada $^{\dagger}$ and Masahiro Goto ${ }^{\dagger *}$

$\dagger$ Department of Applied Chemistry, Graduate School of Engineering, Kyushu University, 744 Motooka, Fukuoka Japan

${ }^{*}$ Corresponding author: Prof. M. Goto, m-goto@mail.cstm.kyushu-u.ac.jp

Number of pages: 3

Number of figures: 5

Number of tables: 0 


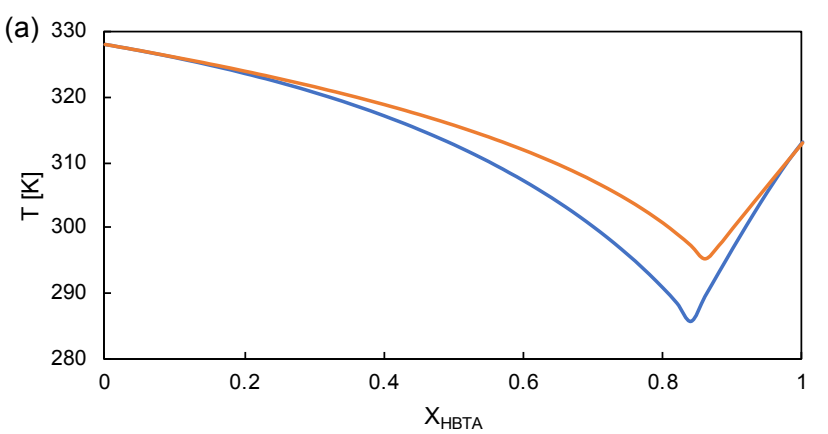

— COSMO-RS _-ideal

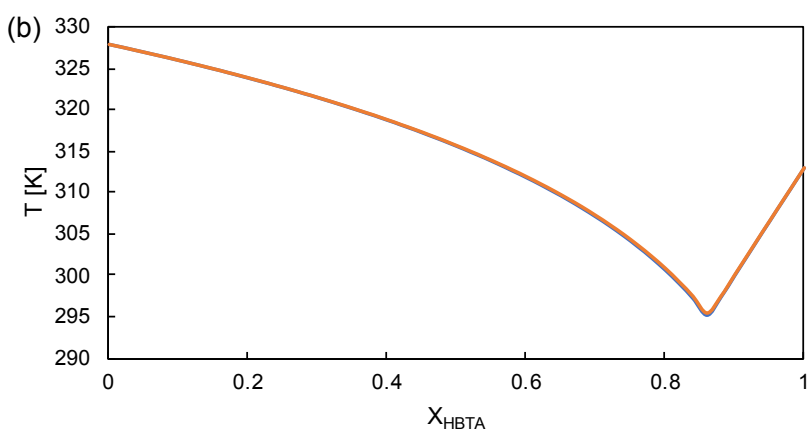

—COSMO-RS Ideal

Fig. S1. The SLE phase diagrams of HBTA/TOPO (a) and HBTA/TPP (b) mixture, that estimated by COSMO-RS and that of the ideal mixture.

(a)

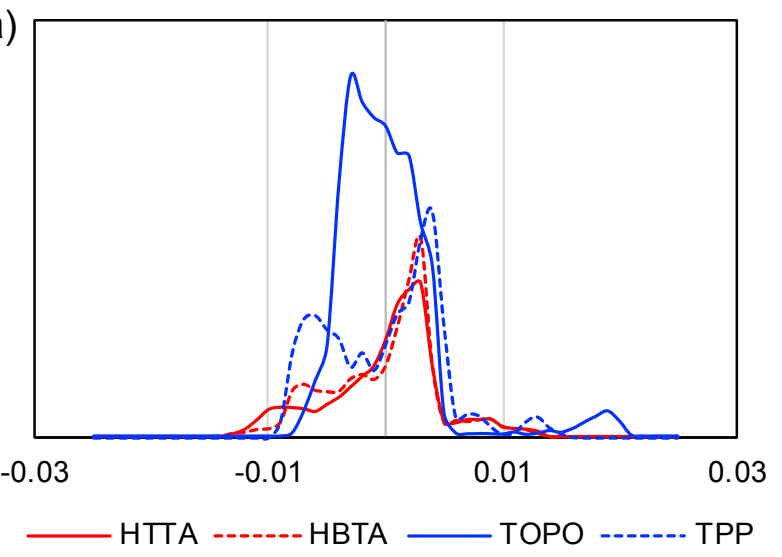

(b)

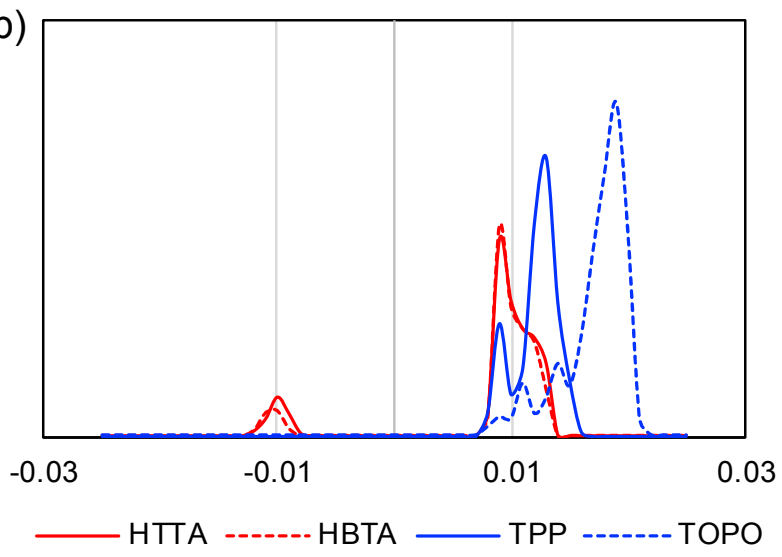

Fig. S2. The sigma profiles of HTTA, HBTA, TOPO and TPP, (a) hole part and (b) hydrogen bonding part.

(a)

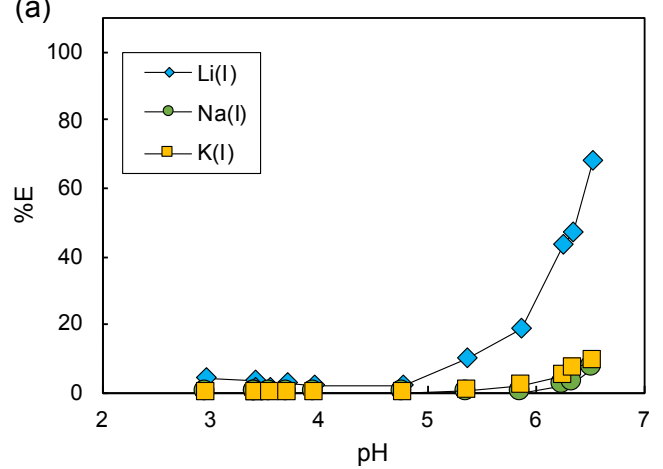

(b)

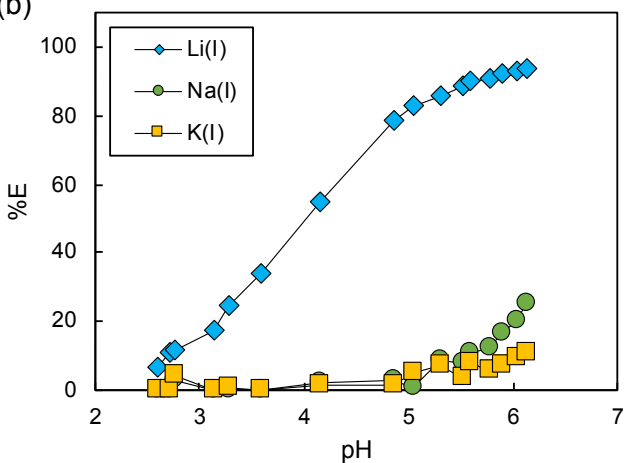

Fig. S3. The extraction performance of Li, Na and $\mathrm{K}$ with (a) HTTA/TPP-ES and (b) HBTA/TOPO-DES as a function of the aqueous equilibrated $\mathrm{pH}$. The aqueous solutions containing $1.0 \mathrm{mmol} \mathrm{dm}^{-3}$ of each metal and prepared as the known $\mathrm{pH}$. Both aqueous and organic phases were contacted with $\mathrm{A} / \mathrm{O}=2: 1$ at $298 \mathrm{~K}$ for $1 \mathrm{~h}$. 


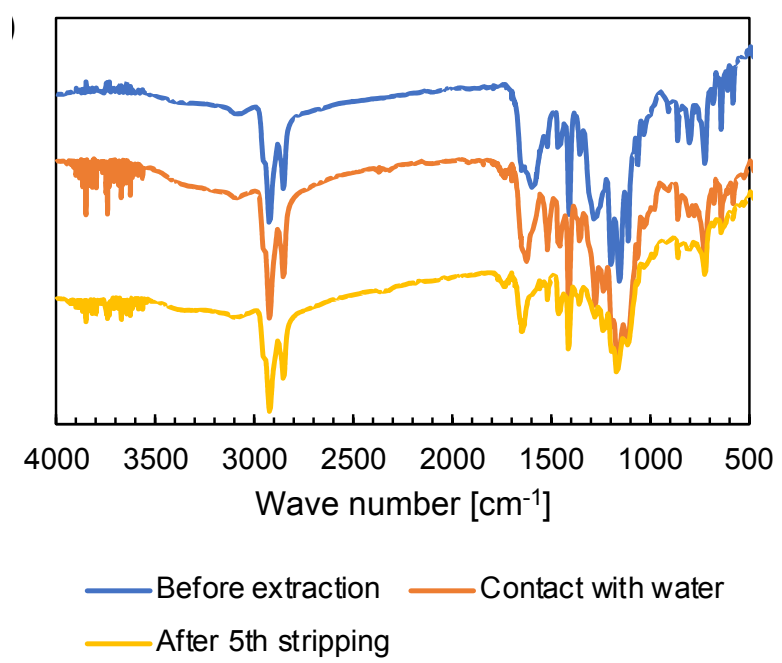

Fig. S4. The FT-IR spectra of HTTA/TOPO-DES before and after reusability test. The FT-IR spectra of the DES after once contact with water was also exhibited to consider the contained water in the DES.

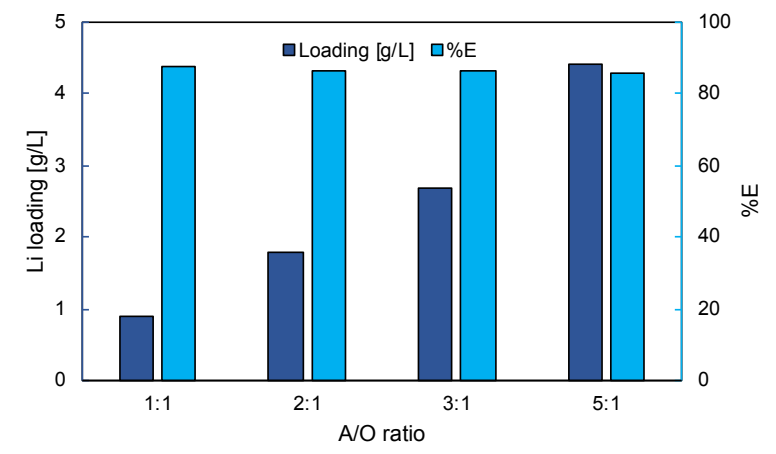

Fig. S5. Extraction of Li with HTTA/TOPO-DES at the various A/O ratio. The aqueous phase containing $1.17 \mathrm{~g} / \mathrm{L}$ of $\mathrm{Li}(\mathrm{I})$ in $0.1 \mathrm{~mol} \mathrm{dm}^{-3} \mathrm{NH}_{4} \mathrm{Cl}$ was contacted to HTTA/TOPO-DES without dilution for $1 \mathrm{~h}$ at $298 \mathrm{~K}$. 